University of Wollongong

Research Online

Faculty of Arts, Social Sciences and Humanities

- Papers

Faculty of Arts, Social Sciences \& Humanities

29-3-2023

\title{
Embodiment as a pedagogical tool to enhance learning
}

\author{
Myrto F. Mavilidi \\ University of Wollongong, myrto@uow.edu.au \\ Kim Ouwehand \\ Erasmus University \\ Mirko Schmidt \\ University of Bern \\ Catarina Pesce \\ University of Rome \\ Phillip D. Tomporowski \\ University Of Georgia
}

See next page for additional authors

Follow this and additional works at: https://ro.uow.edu.au/asshpapers

Research Online is the open access institutional repository for the University of Wollongong. For further information contact the UOW Library: research-pubs@uow.edu.au 


\title{
Embodiment as a pedagogical tool to enhance learning
}

\begin{abstract}
This chapter focuses on practical implications of embodiment to facilitate learning in educational contexts. Starting from a brief historical overview of the scientific debate of action-perception that forms the genesis of embodiment, the chapter progresses to later influential theories. Contemporary trends are discussed in light of theories of embodied cognition, emphasising the importance of body movements in shaping higher-order cognitive processing and how embodied cognitive neuroscience links the brain, the body, and the broader environment. In reviewing the literature, empirical studies with movements are explored in relation to their type of embodiment (e.g., gestures, simulation, whole-body movements, physical activity), educational setting (e.g., preschool, primary school, high school), and learning domain (e.g., language, science). Lastly, embodiment is linked with interoception (i.e., understanding of our body and its needs), to help explain individual and developmental differences. Opportunities and limits of applying embodiment in education are further discussed.
\end{abstract}

\section{Keywords}

enhance, learning, tool, embodiment, pedagogical

\section{Publication Details}

Mavilidi, M. F., Ouwehand, K., Schmidt, M., Pesce, C., Tomporowski, P. D., Okely, A. \& Paas, F. (2022).

Embodiment as a pedagogical tool to enhance learning. In S. A. Stolz (Ed.), The Body, Embodiment, and Education: An Interdisciplinary Approach (pp. 183-203). London, United Kingdom: Routledge.

\section{Authors}

Myrto F. Mavilidi, Kim Ouwehand, Mirko Schmidt, Catarina Pesce, Phillip D. Tomporowski, Anthony D. Okely, and Fred Paas 


\title{
CHAPTER 10
}

\section{Embodiment as a Pedagogical Tool to Enhance Learning}

\author{
MYRTO F. MAVILIDI ${ }^{\mathrm{a}}$ \\ ${ }^{\text {a }}$ University of Wollongong, Australia \\ ORCID.org/0000-0003-2661-8709 \\ KIM OUWEHAND \\ ${ }^{\mathrm{b}}$ Erasmus University Rotterdam, The Netherlands \\ ORCID.org/0000-0002-4440-8433 \\ MIRKO SCHMIDT \\ ${ }^{\mathrm{c}}$ University of Bern, Switzerland \\ ORCID.org/0000-0003-4859-6547 \\ CATERINA PESCE ${ }^{\mathrm{d}}$ \\ 'University of Rome "Foro Italico", Italy \\ ORCID.org/0000-0002-4245-3898
}

PHILLIP D. TOMPOROWSKI ${ }^{\mathrm{e}}$

${ }^{\mathrm{e}}$ University of Georgia, Athens, GA, USA

ORCID.org/0000-0002-6915-1013

ANTHONY OKELYa

${ }^{a}$ University of Wollongong, Australia

ORCID.org/0000-0002-1626-8170

FRED PAAS ${ }^{\mathrm{a} b}$

${ }^{a}$ University of Wollongong, Australia ${ }^{\mathrm{b}}$ Erasmus University Rotterdam, The Netherlands

ORCID.org/0000-0002-1647-5305

\begin{abstract}
This chapter focuses on practical implications of embodiment to facilitate learning in educational contexts. Starting from a brief historical overview of the scientific debate of actionperception that forms the genesis of embodiment, the chapter progresses to later influential theories. Contemporary trends are discussed in light of theories of embodied cognition, emphasising the importance of body movements in shaping higher-order cognitive processing and how embodied cognitive neuroscience links the brain, the body and the broader environment. In reviewing the literature, empirical studies with movements are explored in relation to their type of embodiment (e.g., gestures, simulation, whole-body movements, physical activity), educational setting (e.g., preschool, primary school, high school), and
\end{abstract}


learning domain (e.g., language, science). Lastly, embodiment is linked with interoception (i.e., understanding of our body and its needs), to help explain individual and developmental differences. Opportunities and limits of applying embodiment in education are further discussed.

\section{Introduction}

In this chapter, we describe how embodiment has been used as a pedagogical tool to enhance learning. Starting from a brief historical overview of the philosophical and later scientific debate on action-perception, we unfold the role of embodiment in educational settings. Then we highlight existing theoretical frameworks, as well as empirical studies in gestures, finemotor and gross-motor movements. Lastly, we lay the foundation for connecting the physiological mechanism of interoception to our cognitive functions.

\section{A succinct context of the role of body throughout history}

Although the leading point of view nowadays is an interacting body-brain system, this idea has been debated throughout history. Greek philosophers (e.g., Epicurus, Hippocrates, Socrates) advocated towards psychophysical monism, in which the body and the soul or mind were considered united and dependent upon each other (Bunge, 2014). Plato's disciple, Aristotle (De Anima, trans. 2015) believed that asking whether the body and the soul are one is "as meaningless as to ask whether the wax and the shape given to it by the stamp are one" (e.g., Hardie, 1964). Similar tenets are expressed in the prayer to Gods by the Roman poet Juvenal (The Satires, trans. 1991) "mens sana in corpore sano" to grant human a sound mind in a sound body, and by Marcus Tullius Cicero (On Old Age, trans. 1988), "it is exercise alone that supports the spirits and keeps the mind in vigor".

The seminal approach for contemporary education was adopted with René Descartes' interactionist dualism, in which the rational soul was autonomous, immaterial and immortal (Bunge, 2014). This was contradicted by Pierre Gassendi, who stated that our mind is immaterial, but our ideas exist of things we know by faith and by reason (LoLordo, 2005). The main conceptual differences of Descartes and Gassendi can be highlighted in Descartes' "cogito ergo sum" (i.e., I think, therefore, I am) versus Gassendi's "ambulo ergo sum" (i.e., I walk, therefore, I am). Descartes emphasised the inner mind as our base for existence, whereas Gassendi on moving around in the external world as a base for our existence (Lennon, 2014). The debate of whether the mind and body are separate entities or part of a unified system continued (Powell, 1990). Thomas Hobbes saw it as an indispensable part of the brain, while Baruch Spinoza recognised the importance of the extended substance and thinking as basic elements of human interaction (Bunge, 2014). For John Locke, the body-mind dichotomy was not a real problem, as we are born as to have no innate knowledge after birth ("tabula rasa" or 
blank slate). Thus, it was solely created by us, referring to "physical" or "mental" as a function of how things work, behave and operate (Kim, 2008).

Finally, Immanuel Kant argued that the interaction between the mind's intrinsic features and the world's extrinsic stimuli shape the consciousness, the self (e.g., "I think"), and spatiotemporal continuity (Northoff, 2012). In line with this idea, Charles Darwin considered the mind as a function of the body (Bunge, 2014). James, as an advocate of the Functional School of Psychology, suggested that "without the bodily states following on the perception, the latter would be purely cognitive in form, pale, colorless, destitute of emotional warmth" (Golightly, 1953).

\section{Modern theoretical perspectives}

Primary theories of learning were based on Aristotle's principle of contiguity (i.e., making associations or connections between events, objects, or sensations occurring simultaneously or in close temporal distance (Sheffield, 1951). Pavlov's classical conditioning offered explanations for a stimulus-response process during learning (Konorksi, 1984), whereas radical behaviourism, by Watson, completely differentiated behaviour from mental causes (Fodor, 1981). In Skinner's (1965) operant conditioning, behaviour is not made of automatic or unintentional responses to environmental processes, but is rather voluntary, conscious and intentional. Lastly, logical behaviourism allowed behavioural effects to be attributed to mental causes as interpretation of psychological explanations (Fodor, 1981).

Moving slowly away from the dualistic view towards a unitary mind-body view, modern developmental psychologists included the body and its sensorimotor processes for the development of mind. These primary conceptualisations were used as a repository of knowledge for shaping today's education and teaching methods. As suggested by Kant shaping the contemporary idea of grounded cognition, perception consists of modal representations (e.g., perception and action), and imagery (Barsalou, 2008).

Jean Piaget stressed the role of sensorimotor engagement and physical interactions with the world (i.e., "acting upon objects", "reflective abstraction") in children's perception, cognition and behaviour (Piaget, 1968). The external environment was crucial offering discrete learning experiences, conveyed to children through play (Piaget, 1964). The significance of movements, as part of sociocultural and sociohistorical context of learning and development in children, was expressed by Lev Vygotsky, a contemporary of Piaget ("make-believe play" and imagination; 1967), with conceptual overlaps as well as differences in their theories existing due to their cultural backgrounds (Soviet Union reflected socially-oriented and Switzerland/France personal-oriented influences respectively). Vygotsky believed that the external environment stimuli, mainly the social, historical, cultural and physical experiences, are responsible for moulding children's cognition (Wertsh, 1985). In contrast, Noam Chomsky 
(1975), adopted an amodal view on language learning, involving an abstract innate process of the mind expressed by symbols, without any involvement of the body in it.

Nevertheless, dualistic theories have been well eradicated in the modern educational system, in which the human body is rather sedentary holding no influential role in cognition. An innovative and alternative approach was proposed within the theoretical framework of embodied or grounded cognition, influenced by Piaget, emphasising the role of action for understanding and information processing (Shapiro, 2014). In embodied cognition, cognition is grounded on sensorimotor interactions with the world (Barsalou, 2008).

The close relationship between action, perception and cognition is originated when launching the term "affordances". Firstly introduced by Gibson (1979) after restructuring the "demand character of an object" defined in the "Principles of Gestalt Psychology" (Koffka, 2013), affordances were used to describe the movement-related properties or the different environmental interactions between objects and their related sensorimotor capacities (Garbarini \& Adenzato, 2004; Gibson, 2014). When children get acquainted with conventional objects and their uses, their behaviour is shaped to the affordances of these objects.

Gibson's central point was the explicit denial of the dualism between physical and mental processes. This tenet is in complete contradiction with the Cartesian dichotomy between action and perception. As pointed out by Thelen (2004, p.49), the "foundations of complex human thought and behaviour have their origins in action and are always embedded in a history of acting". Cognition is now perceived as the interaction between the body and mind, action and perception, rational and sensorimotor representations (Garbarini \& Adenzato, 2004). For instance, it was explored whether abstract concepts could be translated into tangible physical concepts through body metaphors (Lakoff \& Johnson, 1980). Varela and colleagues (2016) attempted to operationalise the concept of embodied cognition as dependant on body interactions and sensorimotor experiences, embedded in the biological, cultural, and psychological context.

Wilson (2002) advocated that cognition is situated, occurring in task-relevant inputs and outputs during real time. It also relies on and manipulates the external environment, including bodily states and interactions, to form mental schemas acquired through prior learning (i.e., patterns of thoughts, ideas or behaviour that organise information; Barsalou, 2008; Wilson, 2002). In particular, the human cognitive system can process information that is presented in different modalities (e.g., visual, auditory, motor, tactile) to support relevant cognitive activities (e.g., memory, language, perception, thought, action, emotion; Barsalou et al., 2003). An advantage of multimodal representations (which are chunked together) is that they can be simultaneously processed from different sub-systems (Risko \& Gilbert, 2016), 
imposing lower cognitive demands in the working memory and promoting the flexible use of acquired knowledge and skills (i.e., low cognitive load; Paas \& Sweller, 2012).

Grounded/embodied cognition focuses on how external information mediated by the body and stored in the long-term memory into enhanced multimodal mental representations, facilitates retrieval and reactivation of these representations during recall (Barsalou, 2008). Cognition and sensorimotor systems are part of a highly interconnected system of cells in the brain which are stimulated from signals of the external world communicated via body organs and senses (e.g., eyes, ears, motion; Pulvermüller, 2005, 2013). Hence, the interactions of the human body with the physical environment can enhance higher cognitive processes such as thinking, learning, and problem-solving (Shapiro \& Stolz, 2018). For instance, the "enactment effect", holds that enhanced memory is apparent during subject-performed tasks (i.e., performing task-related actions to remember action words/phrases; Zimmer \& Cohen, 2001).

Through re-enactment/simulation, perceptual, motor, and introspective (e.g., mental, affective) states acquired during experience and interaction with the body, are converted into mental representations. Re-enactment/simulation obtains sensory input, integrates mental imagery across the modalities and thus, facilitates conceptual processing and the construction of enriched mental representations. Its advantage compared to mental imagery is that, while mental imagery is usually conscious, re-enactment/simulation can be unconscious (Barsalou et al., 2003). Obtaining and using this knowledge occurs unconsciously and rather effortlessly (Paas \& Sweller, 2012).

Complementary to this notion, is the cognitive load theory (CLT), focusing on the human cognitive architecture, and particularly its working memory limitations (Sweller, 1988; Sweller et al., 2019). The main aim of CLT is to optimising learning processes by reducing ineffective use of limited working memory resources, i.e., extraneous cognitive load (Paas \& Van Gog, 2006). For example, when making gestures to describe an object, information about its size, and content, is presented simultaneously through different modalities. This manner of information presentation saves the learner (both speaker and listener) temporal and content capacity (combining speech and gestures chunks the size and the object into one element) of the limited working memory system.

In explaining the beneficial opportunities of movements for learning, CLT researchers have incorporated the distinction of Geary (2008) between biologically primary and secondary knowledge (Paas \& Sweller, 2012): Biologically primary knowledge is information humans have evolved to learn, and do not need (much) working memory capacity to process, whereas biologically secondary knowledge needs to be learned explicitly occupying more working memory resources. Paas and Sweller (2012) proposed that information we have evolved to acquire naturally (e.g., human movements, tool use), can facilitate learning of complex skills 
(e.g., mathematics, foreign language). Producing gestures during learning may assist internal cognitive processes by extending the limited working memory capacity from solely internal thoughts to the external world by using the hands (Pouw et al., 2014). Madan and Singhal (2012) suggested that enactment, gestures and exercise may act as simulated actions affecting memory encoding and retrieval.

Emerging evidence in educational technology revealed positive effects of gestures on learning using human computer interaction interfaces (Agostinho et al., 2016; Vuletic et al., 2019). The effectiveness of producing but also observing gestures on learning can be further supported by the putative mirror neuron system hypothesis (Rizzolatti \& Craighero, 2004): performing or observing an action, can activate the same neurons in the motor cortex of the brain, responsible for the execution of these actions (Chong et al., 2008). For instance, Grèzes and Decety (2002) argued that the thought of manageable objects may also result in a partial activation of the motor areas involved in the actual use of these objects. A recent meta-analysis using electroencephalogram confirmed the mirror neuron hypothesis, finding electrical brain activity during the production and observation of actions, and supporting a common neural code for perceptual and motor processes (Fox et al., 2016).

Lastly, embodied cognition research expanded to include gross-motor movements (i.e., physical activity) and their effect on cognition (e.g., executive function). Pesce and BenSoussan (2016) posit that cognitive and motor training combined may build upon complex sensorimotor learning processes that rely on the prefrontal cortex substrate responsible for cognitive control, enhancing the capability to manage the allocation of attentional resources. Skills acquisition achieved via training as a learning process, may be the underpinning mechanism for both motor and cognitive development, apparent in exercise, sports, and performance arts (Tomporowski \& Pesce, 2019).

The qualitative characteristics of physical activity (e.g., task novelty/complexity, selection of suitable mental strategies, rhythm) may act as brain stimulators during combined motor and cognitive training or cognitively engaging physical activity (Diamond \& Ling, 2016; Pesce, 2012). Hence, the integration of physical and cognitive training has been proposed as an approach to boost brain and cognitive health (Moreau \& Tomporowski, 2016; Pesce, 2012). The use of complex motor activities is encouraged to promote changes in cognition and associated outcomes including improved physiological (e.g., neuroplasticity, synaptogenesis) and psychological (e.g., self-esteem, stress reduction) markers (Moreau \& Tomporowski, 2016). Apart from the biophysiological changes elicited in the brain by exercise (see for reviews Tomporowski, 2003; Tomporowski et al., 2008), Best (2010) suggested additional neural connection of brain stimulation pathways coming from the coordinative and cognitive complexity of motor tasks. 
A recent review categorised studies using movements (e.g., physical activity or gestures) on cognition and learning, based on their level of embodiment (i.e., relevance to cognitive/learning task) and integration (i.e., temporal connection with cognitive/learning task; Mavilidi et al., 2018c). Similarly, Skulmowski and Rey (2018) categorised studies according to their level of bodily engagement (i.e., amount of bodily activity involved) and task integration (i.e., relevance with learning task). Both reviews concluded that a blended approach involving task-relevant and integrated physical and learning tasks may show the most pronounced effects in learning performance.

\section{Empirical evidence}

Synthesising existing empirical evidence on embodied cognition in education, we distinguished three main categories of motor actions: gestures, whole-body movements (actual or simulated manipulation of objects involving whole-body postural control), and physical activity.

Gestures include more subtle movements focusing on the area near the hands. An attentional advantage of gestures (i.e., stimuli near the hands) was found on improving spatial attention (Reed et al., 2006), visual working memory (Cosman \& Vecera, 2010; Tseng \& Bridgeman, 2011), and executive functioning (Weidler \& Abrams, 2014). The bimodal (visualproprioceptive) representation of stimuli near the hand recruit additional neural substrates compared to stimuli outside of the peripersonal space (Cosman \& Vecera, 2010; Reed et al., 2006). The beneficial role of gestures has been attested during complex learning, when working memory is challenged, such as reading comprehension (Hostetter, 2011), learning of abstract concepts (Malinverni \& Pares, 2014), second language acquisition (Sweller et al., 2020) and mathematics (Macedonia, 2019).

For example, using a dual-task paradigm for cognitive load measurement (see review of Brunken et al., 2003), gesturing was found to be more frequent during a mental rotation, difficult or novel task (Chu \& Kita, 2011). However, the frequency of gesturing declined when the task became more practiced. Also, children 10-24 months heavily relied on gestures during learning of two-word phrases, but gestures became less apparent when they were able to verbally communicate (Iverson \& Golding-Meadow, 2005).

Cook et al., (2008) asked third and fourth grade children to copy the instructor's hand movements showing the process of solving an equation (verbal condition), repeat the instructor's words (speech condition), or to copy instructor's words and gestures (gesture + speech condition), for solving the same equation problem. No differences were found when tested immediately. After four weeks, higher effects on learning and retention were shown in the gesture + speech, and gesture, compared to the speech conditions. 
Gestures are commonly used to describe visual objects from memory, or objects difficult to remember or encode verbally (i.e., codable vs non-codable objects; Morsella \& Krauss, 2004). Interestingly, gesturing may be integral to the speaking process, regardless of the model or observer. Iverson and Goldin-Meadow (1998) compared gesturing of congenitally blind with sighted children and adolescents. Blind speakers gestured at comparable rate with sighted speakers. Moreover, to test whether blind speakers gestured because they knew that gestures may help listeners' understanding of meaning, blind children were asked to contribute to the same reasoning task as before, but corresponding it to a blind listener. No significant differences in the number of gestures and words produced was shown between the blind speakers addressing to blind listeners when they were compared with a subset of blind speakers from the previous sample matched for level of performance (blind with sighted vs., sighted with sighted vs., blind with blind).

Lastly, pointing and tracing benefited learning: primary school students who were able to trace with their index finger on tablet-based worked out examples related to mathematical problem-solving (i.e., temperature graphs), had higher scores on transfer learning compared to the students in the non-tracing condition (who were only looking; Agostinho et al., 2015). Lajevardi \& colleagues (2017) examined the effects of mimicking gestures on learning foreign language characters from animations and static graphics. University students were randomly assigned to four conditions: animation without gestures, animation with gestures, statics without gestures, or static without gestures. In the gesturing conditions, participants had to mimic gestures simultaneously shown via an instructional video on how to write Mandarin characters, whereas mimicking was not allowed in the non-gesturing conditions. Results demonstrated significant intervention effects benefiting gesturing in the static graphics but not for the animation (movement was already present, thus unnecessary). A second experiment in children aged 6-8 years showed that gesturing was beneficial when learning to write Persian characters from animations was superior over static graphics.

Finally, pointing enhanced memory processes in younger and older adults, when they pointed at picture locations on a touch screen (Ouwehand et al., 2015a). In the pointing group, memory was superior compared to those who only visually observed picture locations. It is suggested that pointing towards locations could help chunk the picture (content) and the location (context) into an integrated memory.

Whole-body movements: Other forms of bodily actions (i.e., fine-motor movements located in the hands and/or legs) semantically connected with the learning targets have been considered in embodied cognition (see for reviews Gallagher \& Lindgren, 2015; Hutto et al., 2015). Similar to gestures, whole-body movements can extend inner cognitive processes and make abstract thoughts more concrete and salient, easier to process and remember. Simulation or 
enactment studies belong in this category. For example, actual and imagined manipulation of toy objects related to a story in a text enhanced children's reading comprehension, and in particular facilitation of the derivation of the meaning (Glenberg, 2017; Glenberg et al., 2004).

Macedonia and Klimesch (2014) found that body actions linked to semantics of words from an artificial language facilitated learning. For example, for the word "seal", the experimenter simulated balancing a ball on her nose, and for "monkey", she raised her right knee and hand pretending a monkey climbing on a tree. University students were assessed at cued-recall (at five time points) over a period of 14 months. Results revealed better and longerlasting learning of vocabulary words in the condition that included movements compared to the condition in which participants only repeated the words aloud.

Cutica et al., (2014) conducted two experiments to investigate the effects of enactment on learning from scientific texts (i.e., circulatory system and the pulling force) in primary school children. In Experiment 1, children were assessed at a recall test. It was found that students who were allowed to enact the information from the text had more correct recollections and discourse-based inferences, and errors than children who were not allowed to enact. In Experiment 2, children were assessed at a recognition test, showing that children who enacted the learning content, were more likely to accept paraphrases, or accept wrong sentences than children who did not enact. Overall, it was concluded that representing concepts through enactment during the learning phase can contribute to the construction of an articulated mental model of the text.

Furthermore, engaging primary school students in cooperative movement learning, shaping forming geometrical shapes with their bodies, facilitated learning of angles in a geometry class (Shoval, 2011). Similarly, Fisher and colleagues (2011) asked children 5-6 years to perform a magnitude comparison task either moving across a spatial number line on a dance mat or on a table PC. Children in the dance mat condition showed a larger improvement on the number line estimation task than the tablet PC condition.

Whole-body simulation can also have a more powerful effect on learning than twodimensional simulation (i.e. desktop simulation): Lindgren and Moshell (2011) engaged middle school students using a prototype mixed reality simulation controlled by body movements (e.g., putting an asteroid in a trajectory around a nearby planet), and a desktop simulation condition to learn about science. It was found that students were able to create more dynamic mental models and better capture the scientific concepts in the whole-body simulation compared to the desktop simulation condition.

Johnson-Glenberg et al. (2014) looked at chemistry titration and disease transmission in high-school students who had to physically move trackable objects over the head or received lectures and hands-on chemistry lab sessions. Higher learning gains and student engagement 
were observed for high-embodiment instructions than regular classroom instruction. The same authors examined the level of embodiment (low vs. high) with the learning platform (mixed reality simulator vs. interactive whiteboard vs. mouse-driven computer desktop) for learning physics (i.e., centripetal force) in first-year Psychology students (Johnson-Glenberg et al., 2016). Significant learning gains at follow up (one week after the instruction) but not at immediate post-test were apparent in the high embodiment conditions, regardless of the learning platform. Whole-body movements can enhance and sustain learning. Nevertheless, the vast majority of research assessed learning outcomes without controlling for affective responses (i.e., children's enjoyment).

Physical activity includes gross-motor movements that produce energy expenditure above a basal level (Centers for Disease Control \& Prevention, 2020).

A body of research has focused on physically active lessons or active breaks embedded in academic time to improve executive functioning and academic achievement (see for reviews Norris et al., 2019; Watson et al., 2017). This research consists of studies examining the acute effects of physical activity through single sessions, and/or the chronic effects of physical activity observed after multiple sessions.

Regarding acute effects, exergame-based physical activity found positive effects on adolescents' executive functions (inhibition and cognitive flexibility; Benzing et al., 2016). The physical activity condition with high levels of cognitive engagement had the highest scores in cognitive flexibility but no differences were found in inhibition, when participants were assigned to physical activity and high levels of cognitive engagement during active video gaming, physical activity with low levels of cognitive engagement during active video gaming, or passive video watching with low levels of cognitive engagement.

Schmidt and colleagues (2016) examined the effects of 10-min of cognitively engaging physical activity breaks on primary school children's attentional performance: Children were assigned to a combination (physical activity with high cognitive demands), cognition (sedentary with high cognitive demands), physical (physical activity with low cognitive demands), or control (sedentary with low cognitive demands) groups. Results revealed that cognitive engagement was an important factor to improve children's focused attention and processing speed.

Regarding the chronic effects of physical activity, a two-week intervention of integrated physical activity enhanced primary school children's foreign vocabulary learning and but not focused attention (Schmidt et al., 2019). Children were assigned to an embodied learning (taskrelevant physical activities), physical activity (task-irrelevant), or a control (sedentary) condition. Cued-recall scores were the highest in the embodied learning condition, followed 
by the physical activity, and lastly control conditions. Interestingly, attentional performance test did not differ across the conditions.

Physically active lessons conducted three times per week for $40 \mathrm{~min}$ in third and fourthgrade children improved spelling scores after four weeks (Mavilidi et al., 2018a), and grammar and punctuation scores after six weeks (Mavilidi et al., 2020). Moreover, math performance in fourth and fifth-grade students was improved after an eight-week intervention integrating physical activity with math (Vazou \& Skrade, 2017).

Lastly, learning gains were also found in preschool children after integrating physical activity in several learning domains (Mavilidi et al., 2019): Children's learning of foreign language words was the highest after four weeks of task-relevant physical activities compared to a gesturing, control (Mavilidi et al., 2015; Toumpaniari et al., 2015), or task-irrelevant physical activity conditions (Mavilidi et al., 2015).

Furthermore, task-relevant physical activities improved preschool children's learning more than task-irrelevant physical activity and sedentary control conditions, immediately and follow up tests on geography (i.e., learning of continents and characteristic animals living in each; Mavilidi et al., 2016), and science (i.e., learning of planets and order based on their distance from the sun; Mavilidi et al., 2017). Lastly, the task-relevant physical activity group had the highest performance on numeracy skills (i.e., counting, number line estimation, numerical magnitude comparison and identification) at immediate post-test and four weeks after the end of the intervention in comparison with a task-irrelevant physical activity, with observing physical activity (but not allowed to perform), and control conditions (Mavilidi et al., 2018b).

\section{Do movements always enhance learning?}

Despite the impressive evidence for the beneficial effects of bodily movements on learning and memory, null, mixed results or reversed effects are not uncommon: Whether movements are effective for learning may rely on all kinds of factors (e.g., characteristics of the learning task, learner, and implementation and types of the movement; timing, observing and or producing movements). Thus, the content and context of the movement and learning components may play a significant role.

The first mechanism explaining mixed findings is the strength of the link between the learning goal and the movements. A meta-analysis of Höffler and Leutner (2007) showed that learning from animations (including observation of movements and gestures) is especially effective when the learning task has a motoric/procedural character (i.e. origami). In this case, the link between task and movement is obviously present. For more complex/abstract learning tasks, more mixed results are found. For example, Post et al. (2013) found that for children with lower levels of language ability learning, using movements (i.e. observing and imitating 
gestures) during learning about a grammar rule had adverse effects on learning, while it had no effect on children with high language abilities. Similar results were observed in adults (Pouw et al., 2016).

Interestingly, a recent meta-analysis of Davis (2018) showed that the effectiveness of an animated agent depends on the humanoid features of the agent (i.e. more humanoid features of the agent seems to have positive effects on the effects of the movements on learning). For movements to be effective, the type of movement may need to match the type of task (i.e., simply pointing at numbers in the problem-solving task did not affect learning; Ouwehand et al., 2015b). Producing movements that are in some way representative for the content or elements of the learning task are the most promising for learning.

In addition, careful consideration is needed for the timing of the movements (e.g., not allowing learners imitate immediately/during instruction), which may be affecting memory (long-term consolidation): the mental processes (e.g., decision making, problem-solving) involved in dual tasking demands performed simultaneously, may offer benefits or impede declarative memory (i.e., semantic, for example recall of facts/events) during the physical and mental challenge (Tomporowski \& Qazi, 2020). Importantly, its effectiveness seems to be largely dependent on timing of memory testing. Although memory testing immediately or soon after encoding may offer null or adverse learning gains, learning gains for consolidation in the long-term memory may arise if memory tests are administered on or after 24 hours of exercise (Tomporowski \& Qazi, 2020).

Lastly, the physical task complexity needs to be considered in relation with the complexity of the learning task. Kamijo et al. (2007) manipulated the physical task complexity (i.e., light, moderate, and hard cycling) during the execution of Erikson Flanker task in adult participants. Results revealed that cognitive function (i.e., P3 latency) is susceptible to motor task difficulty during a cognitive task, with improvements found during light and moderate, but not during hard cycling.

\section{Embodied cognition and interoception}

In the last part of this chapter, we refer to the process of interoception as a mechanism in which bodily movements can support learning. Theories of cognition advocate that information is placed in a semantic memory system linked with the brain's modal systems for action (e.g., proprioception, movement), perception (vision, audition), and introspection (e.g., affect and mental states (Barsalou, 2003). At the same time, we receive signals from our body notifying us about our internal and external (i.e., physical and physiological) conditions (Herbert \& Pollatos, 2012). The term "interoception" was initially introduced to describe visceral sensation (Craig, 2002). This was later extended to include the sense of the internal physiological condition of the body (Craig, 2003). Interoception consists of two forms of perception: 
proprioception (feelings from skin and musculoskeletal organs) and visceroception (feelings from internal organs such as heart; Herbert \& Pollatos, 2012).

Interoceptive concepts of emotions entailed perceptions of body changes (James, 1894). Seth (2013) suggested that emotions can be considered as cognitive evaluations of physiological changes. It is believed that acknowledging the explicit cognitions and beliefs of what has caused the physiological changes to occur, can impact the subjective feeling states and emotional behaviour (Gendron \& Feldman Barrett, 2009). For instance, injecting adrenaline can cause physiological arousal and in turn psychological arousal (i.e., anger or elation varying on the context; Schachter \& Singer, 1962).

Damasio (1996) attempted to connect interoception and cognitive function, advocating the existence of somatic markers in the prefrontal cortex. The homeostatic control of the internal bodily state may be related to mental processes and their neural substrates, with interoceptive pathways influencing perception, cognition, emotion and behavior (Critchley \& Harrison, 2013) as well as motivation, social cognition, and self-awareness (Tsakiris \& Critsley, 2016). As such, embodied self-awareness is believed to be grounded on the neural monitoring and representation of afferent body signals. This assumption led to the generation of the sense of the physical "I" (i.e., how we perceive and respond to our body signals), guiding executive function (such as goal-directed cognitive processing, behavioural and decisionmaking; Babo-Rebelo et al., 2016; Craig, 2002). Importantly, the role of individual differences is fundamental (Tsakiris \& Critsley, 2016).

Apart from the physiological parameters, selfhood entails the experience of identifying and owning with a particular body, and metacognitive aspects of subjective "I" (such as linking of episodic memories of "I" over time; Metzinger, 2004; Northoff \& Bermpohl, 2004). Specifically, the "anterior insular cortex" area in the brain, responsible for emotional feelings, is able to monitor physiological changes, as well as integrate interoceptive representations linked with visceral control, conscious and emotional awareness of the selfhood (Seth, 2013).

For example, evidence of the basis of bodily self-identification can be seen when connecting vision, touch and proprioception during an illusion (Botvinick \& Cohen, 1998). Participants thought the artificial hand as their own, when it was presented simultaneously with their real hand, while they were asked to focus their visual attention on the artificial limb. Similar effects were observed during face recognition when participants were asked to touch the partner's face who were simultaneously viewing (Sforza et al., 2010). Finally, virtual reality can create the illusion of mislocalising participants' bodies toward a virtual body presented in front of them (Lenggenhager et al., 2007).

Expanding this area of research to include interoception, Perakakis and colleagues (2017) explored the relationship between regular exercise and electroencephalogram (EEG) 
responses to afferent cardiac signals. Different neural processing of afferent cardiac activity observed in physically active compared to sedentary individuals are attributed to the enhanced interoceptive sensitivity and in turn improved sustained attention of triathletes. This research emphasises the importance of neural monitoring of visceral signals in cognitive function (i.e., perceptual processing) and generation of sense of "self". Cognitive fatigue may contribute to different predictions in regard to the expected sensory consequences during exercise (McMorris, in press).

In addition, worse detection and subsequent memory of words were apparent in individuals during systole compared to diastole (Garfinkel et al., 2013). These deteriorated memory effects were evident in individuals with low interoceptive sensitivity (measured by heartbeat counting task), and for words which have been detected less confidently. The authors concluded that metacognition (i.e., perceptual confidence) and interoceptive sensitivity may mediate the relationship between cardiovascular arousal and cognitive function.

Similarly, young adults with good or poor perception of the heart activity were shown positive, negative, or neutral words (ranked with high, low, or middle valence/pleasantness while measuring heart rate and skin conductance (Werner et al., 2010). Participants' implicit memory during encoding was assessed. Findings revealed that participants with good cardiac perception significantly completed more words of positive and negative words previously presented whereas no differences were found between physiological measures and neutral words.

Finally, Matthias et al., (2009) investigated whether interoceptive awareness is linked with attentional performance. Based on the heartbeat perception task, female participants were categorised into having high or poor interoceptive awareness. After being assessed in the selective and divided attention, it was demonstrated that the heartbeat perception scores significantly differed among participants with high and poor interoceptive awareness. Importantly, good heartbeat perceivers performed better in both selective and divided attention tasks.

\section{Conclusions}

The purpose of this chapter was to highlight how embodiment can be effectively used in education, providing existing evidence on the positive effects of movements on learning. Our goal is not to dispute the traditional teaching methods that render a predominant sedentary approach exclusively using the mind. Instead, we suggest an alternative instructional approach, advocating towards a central role of the body in cognition. Our chapter explored theories and empirical in gestures, fine-motor and gross-motor movements. Lastly, we attempted to unveil how the physiological mechanisms of interoception respond to our cognitive function. Our main conclusions draw upon this line of research. 
Going "back to the future", we are entitled to reject the Cartesian dichotomy of body and mind and accept the Greek and Roman ancestors' views of a united body and mind. Nevertheless, despite opportunities that movements can be applied to learning, their effectiveness is not always guaranteed and can be limited in the contextual circumstances.

During motor and cognitive development, possibilities for action are created and constrained by the body and the environment. Adolph and Hoch (2019) pinpointed that motor development is embodied (depending on the different bodily states), embedded (depending on the external environment), and enculturated (depending on social, historical and cultural cues;). Through this way, it has the potential to instigate cognitive development.

An embodiment-based education (e.g., gestures, enactment, simulation, or physical activity) can be applied in diverse settings (e.g., preschool, primary school, University) and learning domains (e.g., language, science, mathematics; Mavilidi et al., 2018c; Mavilidi et al., 2019). Embodiment effects, as a form of action experience, seem prevalent throughout childhood and adulthood (Kontra et al., 2012). Neuroscientific evidence could be used as a support tool, offering guidance in education, unfolding how brain patterns function during cognitive processing (e.g., language and mathematical thinking; Macedonia, 2019).

Promoting hands-on opportunities in an active learning environment is also recommended to contribute to holistic and conclusive learning across the life span. Diamond (2010, p.1) notes: "for the best academic outcomes, we should not narrowly focus on academics but to also address children's social, emotional, and physical development". Movement integration opens new pathways as a pedagogical strategy and a method of transferable abilities that foster academic performance (Madsen \& Aggerholm, 2020). In fact, as proposed in the taxonomy of transfer of learning by Barnett and Ceci (2002), transfer is not only a matter of content, but also of context (e.g., physical, social, functional, temporal context).

Movement integration including physical activity has been successfully implemented in school settings (Vazou et al., 2020), and is believed to lead to higher cognitive and learning outcomes than mere aerobic exercise interventions or regular practices of teaching in the classrooms (Vazou et al., 2019). Task diversity and novelty, effort, and mental engagement may be the underpinning mechanisms that can transform physical activity into meaningful learning experiences for cognitive development (Pesce et al., 2019; Tomporowski et al., 2015).

Finally, a new line of research diverges exercise-cognition with brain-heart interactions, to investigate the underlying mechanisms of physical activity and cognition leading to brain and cognitive improvement by enhanced embodied awareness (Perakakis et al., 2017; Pesce \& Ben-Soussan, 2016). Studies including the body-mind interaction such as cardiac perception to improve heartbeat awareness or dancing and interoceptive meditation during execution of cognitive tasks may provide a fruitful research path for the future. 


\section{References}

Adolph, K. E., \& Hoch, J. E. (2019). Motor development: Embodied, embedded, enculturated, and enabling. Annual Review of Psychology, 70, 141-164.

Agostinho, S., Ginns, P., Tindall-Ford, S., Mavilidi, M. F., \& Paas, F. (2016). 'Touch the screen': linking touch-based educational technology with learning-a synthesis of current research. In L. Lim \& R. Atkinson, (Eds.) Educational technologies: Challenges, applications and learning outcomes (pp. 33-57). Nova Science Publishers.

Agostinho, S., Tindall-Ford, S., Ginns, P., Howard, S. J., Leahy, W., \& Paas, F. (2015). Giving learning a helping hand: finger tracing of temperature graphs on an iPad. Educational Psychology Review, 27(3), 427-443.

Aristotle (2015). De Anima (On the Soul) (J.A. Smith, Transl.). Aeterna Press.

Babo-Rebelo, M., Richter, C. G., \& Tallon-Baudry, C. (2016). Neural responses to heartbeats in the default network encode the self in spontaneous thoughts. Journal of Neuroscience, 36(30), 7829-7840.

Barnett, S. M., \& Ceci, S. J. (2002). When and where do we apply what we learn?: A taxonomy for far transfer. Psychological Bulletin, 128(4), 612-637.

Barsalou, L. W. (2008). Grounded cognition. Annual Review of Psychology, 59, 617-645.

Barsalou, L. W., Simmons, W. K., Barbey, A. K., \& Wilson, C. D. (2003). Grounding conceptual knowledge in modality-specific systems. Trends in Cognitive Sciences, 7(2), 84-91.

Benzing, V., Heinks, T., Eggenberger, N., \& Schmidt, M. (2016). Acute cognitively engaging exergame-based physical activity enhances executive functions in adolescents. PLoS ONE, 11(12), e0167501.

Best, J. R. (2010). Effects of physical activity on children's executive function: Contributions of experimental research on aerobic exercise. Developmental Review, 30(4), 331-351.

Botvinick, M., \& Cohen, J. (1998). Rubber hands 'feel' touch that eyes see. Nature, 391(6669), 756-756.

Brunken, R., Plass, J. L., \& Leutner, D, (2003). Direct measurement of cognitive load in multimedia learning. Educational Psychologist, 38, 53-61.

Bunge, M. (2014). The mind-body problem: A psychobiological approach. Pergamon Press.

Centers for Disease Control \& Prevention, 2020. Retrieved June 26, 2020 from https://www.cdc.gov/physicalactivity/about-physical-activity/index.html

Cicero, M. T. (1988). Cato Maior De Senectute. Ed. J. G. F. Powell. Cambridge University Press. Chomsky, N. (1975). Reflections on Language. Pantheon Books.

Chong, T. T. J., Cunnington, R., Williams, M. A., Kanwisher, N., \& Mattingley, J. B. (2008). fMRI adaptation reveals mirror neurons in human inferior parietal cortex. Current Biology, 18(20), 1576-1580. 
Chu, M., \& Kita, S. (2011). The nature of gestures' beneficial role in spatial problem solving. Journal of Experimental Psychology: General, 140, 102-116.

Cook, S. W., Mitchell, Z., \& Goldin-Meadow, S. (2008). Gesturing makes learning last. Cognition, $106,1047-1058$.

Cosman, J. D., \& Vecera, S. P. (2010). Attention affects visual perceptual processing near the hand. Psychological Science, 21, 1254-1258.

Craig, A. D. (2002). How do you feel? Interoception: the sense of the physiological condition of the body. Nature Reviews Neuroscience, 3(8), 655-666.

Craig, A. D. (2003). Interoception: The sense of the physiological condition of the body. Current Opinion in Neurobiology, 13, 500-505.

Critchley, H. D., \& Harrison, N. A. (2013). Visceral influences on brain and behavior. Neuron, 77(4), 624-638.

Cutica, I., Ianì, F., \& Bucciarelli, M. (2014). Learning from text benefits from enactment. Memory \& Cognition, 42(7), 1026-1037.

Damasio, A. R. (1996). The somatic marker hypothesis and the possible functions of the prefrontal cortex. Philosophical Transactions of the Royal Society of London. Series B: Biological Sciences, 351(1346), 1413-1420.

Davis, R. O. (2018). The impact of pedagogical agent gesturing in multimedia learning environments: A meta-analysis. Educational Research Review, 24, 193-209.

Diamond, A. (2010). The evidence base for improving school outcomes by addressing the whole child and by addressing skills and attitudes, not just content. Early Education and Development, 21(5), 780-793.

Diamond, A., \& Ling, D. S. (2016). Conclusions about interventions, programs, and approaches for improving executive functions that appear justified and those that, despite much hype, do not. Developmental Cognitive Neuroscience, 18, 34-48.

Fischer, U., Moeller, K., Bientzle, M., Cress, U., \& Nuerk, H. C. (2011). Sensori-motor spatial training of number magnitude representation. Psychonomic Bulletin \& Review, 18(1), 177-183.

Fodor, J. A. (1981). The mind-body problem. Scientific American, 244(1), 114-123.

Fox, N. A., Bakermans-Kranenburg, M. J., Yoo, K. H., Bowman, L. C., Cannon, E. N., Vanderwert, R. E., ... \& Van IJzendoorn, M. H. (2016). Assessing human mirror activity with EEG mu rhythm: A meta-analysis. Psychological Bulletin, 142(3), 1-46.

Gallagher, S., \& Lindgren, R. (2015). Enactive metaphors: Learning through full-body engagement. Educational Psychology Review, 27(3), 391-404.

Garbarini, F., \& Adenzato, M. (2004). At the root of embodied cognition: Cognitive science meets neurophysiology. Brain and Cognition, 56(1), 100-106. 
Garfinkel, S. N., Barrett, A. B., Minati, L., Dolan, R. J., Seth, A. K., \& Critchley, H. D. (2013). What the heart forgets: Cardiac timing influences memory for words and is modulated by metacognition and interoceptive sensitivity. Psychophysiology, 50(6), 505-512.

Geary, D. C. (2008). An evolutionarily informed education science. Educational Psychologist, 43, $179-195$.

Gendron, M., \& Feldman Barrett, L. (2009). Reconstructing the past: A century of ideas about emotion in psychology. Emotion Review, 1(4), 316-339.

Gibson, J. J. (1979). The theory of affordances. In J.J. Gieseking, W. and Mangold (Eds.), The people place and space reader (pp. 56-60). Routledge.

Gibson, J. J. (2014). The ecological approach to visual perception: classic edition. Psychology Press.

Glenberg, A. M. (2017). How reading comprehension is embodied and why that matters. International Electronic Journal of Elementary Education, 4(1), 5-18.

Glenberg, A. M., Gutierrez, T., Levin, J. R., Japuntich, S., \& Kaschak, M. P. (2004). Activity and imagined activity can enhance young children's reading comprehension. Journal of Educational Psychology, 96(3), 424-436.

Golightly, C. L. (1953). The James-Lange theory: a logical post-mortem. Philosophy of Science, 20(4), 286-299.

Grèzes, J., \& Decety, J. (2002). Does visual perception of object afford action? Evidence from a neuroimaging study. Neuropsychologia, 40(2), 212-222.

Hardie, W. F. (1964). Aristotle's treatment of the relation between the soul and the body. The Philosophical Quarterly (1950-), 14(54), 53-72.

Herbert, B. M., \& Pollatos, O. (2012). The body in the mind: on the relationship between interoception and embodiment. Topics in Cognitive Science, 4(4), 692-704.

Höffler, T. N., \& Leutner, D. (2007). Instructional animation versus static pictures: A metaanalysis. Learning and Instruction, 17, 722-738.

Hostetter, A. B. (2011). When do gestures communicate? A meta-analysis. Psychological Bulletin, 137(2), 297-315.

Hutto, D. D., Kirchhoff, M. D., \& Abrahamson, D. (2015). The enactive roots of STEM: Rethinking educational design in mathematics. Educational Psychology Review, 27(3), 371-389.

Iverson, J. M., \& Goldin-Meadow, S. (1998). Why people gesture when they speak. Nature, 396(6708), 228-228.

Iverson, J. M., \& Goldin-Meadow, S. (2005). Gesture paves the way for language development. Psychological Science, 16, 367-371.

James, W. (1894). Discussion: The physical basis of emotion. Psychological Review, 1(5), 516 529. 
Juvenal (1991). The Satires (Niall Rudd, Transl.). Oxford University Press.

Johnson-Glenberg, M. C., Birchfield, D. A., Tolentino, L., \& Koziupa, T. (2014). Collaborative embodied learning in mixed reality motion-capture environments: Two science studies. Journal of Educational Psychology, 106(1), 86-104.

Johnson-Glenberg, M. C., Megowan-Romanowicz, C., Birchfield, D. A., \& Savio-Ramos, C. (2016). Effects of embodied learning and digital platform on the retention of physics content: Centripetal force. Frontiers in Psychology, 7, 1819.

Kamijo, K., Nishihira, Y., Higashiura, T., \& Kuroiwa, K. (2007). The interactive effect of exercise intensity and task difficulty on human cognitive processing. International Journal of Psychophysiology, 65(2), 114-121.

Kim, H. K. (2008). Locke and the mind-body problem: an interpretation of his agnosticism. Philosophy, 83(4), 439-458.

Koffka, K. (2013). Principles of Gestalt psychology (Vol. 44). Routledge.

Konorski, J. (1984). Conditioned reflexes and neuron organization. Cambridge University Press.

Kontra, C., Goldin-Meadow, S., \& Beilock, S. L. (2012). Embodied learning across the life span. Topics in Cognitive Science, 4(4), 731-739.

Lajevardi, N., Narang, N. S., Marcus, N., \& Ayres, P. (2017). Can mimicking gestures facilitate learning from instructional animations and static graphics?. Computers \& Education, 110, 6476.

Lakoff, G., \& Johnson, M. (1980). Metaphors we live by. University of Chicago Press.

Lenggenhager, B., Tadi, T., Metzinger, T., \& Blanke, O. (2007). Video ergo sum: manipulating bodily self-consciousness. Science, 317(5841), 1096-1099.

Lennon, T. M. (2014). The battle of the gods and giants: The legacies of Descartes and Gassendi, 1655-1715. Princeton University Press.

Lindgren, R., \& Moshell, J. M. (2011, June). Supporting children's learning with body-based metaphors in a mixed reality environment. In C. Quintana, S. Price \& T. Moher Proceedings of the 10th International Conference on Interaction Design and Children (pp. 177-180).

LoLordo, A. (2005). 'Descartes's one rule of logic': Gassendi's critique of the doctrine of clear and distinct perception. British Journal for the History of Philosophy, 13(1), 51-72.

Macedonia, M. (2019). Embodied Learning: Why at school the mind needs the body. Frontiers in Psychology, 10, 2098.

Macedonia, M., \& Klimesch, W. (2014). Long-term effects of gestures on memory for foreign language words trained in the classroom. Mind, Brain and Education, 8(2), 74-88.

Madan, C. R., \& Singhal, A. (2012). Using actions to enhance memory: Effects of enactment, gestures, and exercise on human memory. Frontiers in Psychology, 3, 507. 
Madsen, K. L., \& Aggerholm, K. (2020). Embodying education-a bildung theoretical approach to movement integration. Nordic Journal of Studies in Educational Policy, 6(2), 1-8.

Malinverni, L., \& Pares, N. (2014). Learning of abstract concepts through full-body interaction: a systematic. Educational Technology \& Society, 17(4), 100-116.

Matthias, E., Schandry, R., Duschek, S., \& Pollatos, O. (2009). On the relationship between interoceptive awareness and the attentional processing of visual stimuli. International Journal of Psychophysiology, 72(2), 154-159.

Mavilidi, M. F., Lubans, D. R., Eather, N., Morgan, P. J., \& Riley, N. (2018a). Preliminary efficacy and feasibility of "Thinking while moving in English": a program with physical activity integrated into primary school English lessons. Children, 5(8), 1-13.

Mavilidi, M. F., Lubans, D. R., Miller, A., Eather, N., Morgan, P. J., Lonsdale, C., \& Riley, N. (2020). Impact of the "Thinking while Moving in English" intervention on primary school children's physical activity and academic outcomes: A cluster randomized controlled trial. International Journal of Educational Research, 102, 1-14.

Mavilidi, M. F., Okely, A. D., Chandler, P., \& Paas, F. (2016). Infusing physical activities into the classroom: Effects on preschool children's geography learning. Mind, Brain, and Education, 10(4), 256-263.

Mavilidi, M. F., Okely, A. D., Chandler, P., \& Paas, F. (2017). Effects of integrating physical activities into a science lesson on preschool children's learning and enjoyment. Applied Cognitive Psychology, 31(3), 281-290.

Mavilidi, M. F., Okely, A. D., Chandler, P., Cliff, D. P., \& Paas, F. (2015). Effects of integrated physical exercises and gestures on preschool children's foreign language vocabulary learning. Educational Psychology Review, 27(3), 413-426.

Mavilidi, M. F., Okely, A., Chandler, P., Domazet, S. L., \& Paas, F. (2018b). Immediate and delayed effects of integrating physical activity into preschool children's learning of numeracy skills. Journal of Experimental Child Psychology, 166, 502-519.

Mavilidi, M. F., Ruiter, M., Schmidt, M., Okely, A. D., Loyens, S., Chandler, P., \& Paas, F. (2018c). A narrative review of school-based physical activity for enhancing cognition and learning: The importance of relevancy and integration. Frontiers in Psychology, 9, 2079.

Mavilidi, M., Ouwehand, K., Okely, A. D., Chandler, P., \& Paas, F. (2019). Embodying learning through physical activity and gestures in preschool children. In S. Tindall-Ford, S. Agostinho \& J. Sweller (Eds.), Advances in Cognitive Load Theory: Rethinking Teaching (pp. 103-118). Routledge.

McMorris, T. (in press). Cognitive fatigue effects on physical performance: The role of interoception. Sports Medicine.

Metzinger, T. (2004). Being no one: The self-model theory of subjectivity. MIT Press. 
Moreau, D., \& Tomporowski, P. D. (2018). 10 complex motor activities to enhance cognition. In M. L. Cappuccio (Ed.), Handbook of embodied cognition and sport psychology, 273. MIT Press.

Morsella, E., \& Krauss, R. M. (2004). The role of gestures in spatial working memory and speech. The American Journal of Psychology, 411-424.

Norris, E., van Steen, T., Direito, A., \& Stamatakis, E. (2019). Physically active lessons in schools and their impact on physical activity, educational, health and cognition outcomes: a systematic review and meta-analysis. British Journal of Sports Medicine, 7, 1819.

Northoff, G. (2012). Immanuel Kant's mind and the brain's resting state. Trends in Cognitive Sciences, 16(7), 356-359.

Northoff, G., \& Bermpohl, F. (2004). Cortical midline structures and the self. Trends in Cognitive Sciences, 8(3), 102-107.

Ouwehand, K., van Gog, T. \& Paas, F. (2015a). Effects of gestures on older adults' learning from video-based models. Applied Cognitive Psychology, 29 (1), 115-128.

Ouwehand, K., Van Gog, T., \& Paas, F. (2015b). Effects of pointing compared to naming and observing during encoding on item and source memory in young and older adults. Memory, 24(9), 1243-1255.

Paas, F., \& Sweller, J. (2012). An evolutionary upgrade of cognitive load theory: Using the human motor system and collaboration to support the learning of complex cognitive tasks. Educational Psychology Review, 24, 27-45.

Paas, F., \& Van Gog, T. (2006). Optimizing worked example instruction: Different ways to increase germane cognitive load. Learning and Instruction, 16, 87-91.

Perakakis, P., Luque-Casado, A. L., Ciria, L., Ivanov, P., \& Sanabria, D. (2017). Neural responses to heartbeats of physically trained and sedentary young adults. BioRxiv, 156802.

Pesce, C. (2012). Shifting the focus from quantitative to qualitative exercise characteristics in exercise and cognition research. Journal of Sport and Exercise Psychology, 34(6), 766-786.

Pesce, C., \& Ben-Soussan, T. D. (2016). "Cogito ergo sum” or "ambulo ergo sum”? New perspectives in developmental exercise and cognition research. In T. McMorris (Ed.), Exercisecognition interaction: Neuroscience perspectives (pp. 251-282). Elsevier Academic Press.

Pesce, C., Croce, R., Ben-Soussan, T. D., Vazou, S., McCullick, B., Tomporowski, P. D., \& Horvat, M. (2019). Variability of practice as an interface between motor and cognitive development. International Journal of Sport and Exercise Psychology, 17(2), 133-152.

Piaget, J. (1964). Cognitive development in children: Piaget development and learning. Journal of Research in Science Teaching, 2, 176-186.

Piaget, J. (1968). Genetic epistemology (E. Duckworth, Trans.). Columbia University Press. 
Post, L. S., Van Gog, T., Paas, F., \& Zwaan, R. A. (2013). Effects of simultaneously observing and making gestures while studying grammar animations on cognitive load and learning. Computers in Human Behavior, 29, 1450-1455.

Pouw, W. T., De Nooijer, J. A., Van Gog, T., Zwaan, R. A., \& Paas, F. (2014). Toward a more embedded/extended perspective on the cognitive function of gestures. Frontiers in Psychology, 5, 359.

Pouw, W. T., Mavilidi, M. F., Van Gog, T., \& Paas, F. (2016). Gesturing during mental problem solving reduces eye movements, especially for individuals with lower visual working memory capacity. Cognitive Processing, 17(3), 269-277.

Powell, T. (1990). Kant's Theory of Self-Consciousness. Clarendon Press.

Pulvermüller, F. (2005). Brain mechanisms linking language and action. Nature Reviews Neuroscience, 6, 576-582.

Pulvermüller, F. (2013). Semantic embodiment, disembodiment or misembodiment? In search of meaning in modules and neuron circuits. Brain and Language, 127, 86-103.

Reed, C. L., Grubb, J. D., \& Steele, C. (2006). Hands up: Attentional prioritization of space near the hand. Journal of Experimental Psychology: Human Perception and Performance, 32, 166177.

Risko, E. F., \& Gilbert, S. J. (2016). Cognitive offloading. Trends in Cognitive Sciences, 20(9), 676-688.

Rizzolatti, G., \& Craighero, L. (2004). The mirror-neuron system. Annual Review of Neuroscience, 27, 169-192.

Schachter, S., \& Singer, J. (1962). Cognitive, social, and physiological determinants of emotional state. Psychological Review, 69(5), 379-399.

Schmidt, M., Benzing, V., \& Kamer, M. (2016). Classroom-based physical activity breaks and children's attention: cognitive engagement works!. Frontiers in Psychology, 7, 1474.

Schmidt, M., Benzing, V., Wallman-Jones, A., Mavilidi, M. F., Lubans, D. R., \& Paas, F. (2019). Embodied learning in the classroom: Effects on primary school children's attention and foreign language vocabulary learning. Psychology of Sport and Exercise, 43, 45-54.

Seth, A. K. (2013). Interoceptive inference, emotion, and the embodied self. Trends in Cognitive Sciences, 17(11), 565-573.

Sforza, A., Bufalari, I., Haggard, P., \& Aglioti, S. M. (2010). My face in yours: Visuo-tactile facial stimulation influences sense of identity. Social Neuroscience, 5(2), 148-162.

Shapiro, L. (Ed.). (2014). The Routledge handbook of embodied cognition. Routledge.

Shapiro, L., \& Stolz, S. A. (2019). Embodied cognition and its significance for education. Theory and Research in Education, 17(1), 19-39. 
Sheffield, F. D. (1951). The contiguity principle in learning theory. Psychological Review, 58(5), 362-367.

Shoval, E. (2011). Using mindful movement in cooperative learning while learning about angles. Instructional Science, 39(4), 453-466.

Skinner, B. F. (1965). Science and human behavior. Simon and Schuster.

Skulmowski, A., \& Rey, G. D. (2018). Embodied learning: introducing a taxonomy based on bodily engagement and task integration. Cognitive Research: Principles and Implications, 3(1), 1-10.

Sweller, J. (1988). Cognitive load during problem solving: Effects on learning. Cognitive Science, $12,257-285$.

Sweller, J., van Merriënboer, J. J., \& Paas, F. (2019). Cognitive architecture and instructional design: 20 years later. Educational Psychology Review, 31(2), 261-292.

Sweller, N., Shinooka-Phelan, A., \& Austin, E. (2020). The effects of observing and producing gestures on Japanese word learning. Acta Psychologica, 207, 103079.

Thelen, E. (2004). The central role of action in typical and atypical development: A dynamic systems perspective. In I.J. Stockman (Ed.), Movement and action in learning and development: Clinical implications for pervasive developmental disorders (pp. 49-73). Elsevier Academic Press.

Tomporowski, P. D. (2003). Cognitive and behavioral responses to acute exercise in youths: A review. Pediatric Exercise Science, 15(4), 348-359.

Tomporowski, P. D., \& Pesce, C. (2019). Exercise, sports, and performance arts benefit cognition via a common process. Psychological Bulletin, 145(9), 929-951.

Tomporowski, P. D., \& Qazi, A. S. (2020). Cognitive-motor dual task interference effects on declarative memory: A theory-based review. Frontiers in Psychology, 11, 1015.

Tomporowski, P. D., Davis, C. L., Miller, P. H., \& Naglieri, J. A. (2008). Exercise and children's intelligence, cognition, and academic achievement. Educational psychology review, 20(2), 111131.

Tomporowski, P. D., McCullick, B., Pendleton, D. M., \& Pesce, C. (2015). Exercise and children's cognition: the role of exercise characteristics and a place for metacognition. Journal of Sport and Health Science, 4(1), 47-55.

Toumpaniari, K., Loyens, S., Mavilidi, M. F., \& Paas, F. (2015). Preschool children's foreign language vocabulary learning by embodying words through physical activity and gesturing. Educational Psychology Review, 27(3), 445-456.

Tsakiris, M., \& Critchley, H. (2016). Interoception beyond homeostasis: affect, cognition and mental health. Philosophical Transactions of the Royal Society B, 371, 1-6.

Tseng, P., \& Bridgeman, B. (2011). Improved change detection with nearby hands. Experimental Brain Research, 209, 257-269. 
Varela, F. J., Thompson, E., \& Rosch, E. (2016). The embodied mind: Cognitive science and human experience. MIT press.

Vazou, S., \& Skrade, M. A. (2017). Intervention integrating physical activity with math: math performance, perceived competence, and need satisfaction. International Journal of Sport and Exercise Psychology, 15(5), 508-522.

Vazou, S., Pesce, C., Lakes, K., \& Smiley-Oyen, A. (2019). More than one road leads to Rome: a narrative review and meta-analysis of physical activity intervention effects on cognition in youth. International Journal of Sport and Exercise Psychology, 17(2), 153-178.

Vazou, S., Webster, C. A., Stewart, G., Candal, P., Egan, C. A., Pennell, A., \& Russ, L. B. (2020). A systematic review and qualitative synthesis resulting in a typology of elementary classroom movement integration interventions. Sports Medicine-Open, 6(1), 1-16.

Visscher, C. (2016). Physically active math and language lessons improve academic achievement: a cluster randomized controlled trial. Pediatrics, 137(3).

Vuletic, T., Duffy, A., Hay, L., McTeague, C., Campbell, G., \& Grealy, M. (2019). Systematic literature review of hand gestures used in human computer interaction interfaces. International Journal of Human-Computer Studies, 129, 74-94.

Vygotsky, L. S. (1967). Play and its role in the mental development of the child. Soviet Psychology, $5(3), 6-18$.

Watson, A., Timperio, A., Brown, H., Best, K., \& Hesketh, K. D. (2017). Effect of classroombased physical activity interventions on academic and physical activity outcomes: a systematic review and meta-analysis. International Journal of Behavioral Nutrition and Physical Activity, 14(1), 1-24.

Weidler, B. J., \& Abrams, R. A. (2014). Enhanced cognitive control near the hands. Psychonomic Bulletin \& Review, 21, 462-469.

Werner, N. S., Peres, I., Duschek, S., \& Schandry, R. (2010). Implicit memory for emotional words is modulated by cardiac perception. Biological Psychology, 85(3), 370-376.

Wertsch, J. V. (1985). Vygotsky and the social formation of mind. Harvard University Press.

Wilson, M. (2002). Six views of embodied cognition. Psychonomic Bulletin \& Review, 9, 625636.

Zimmer, H. D., \& Cohen, R. L. (2001). Remembering Actions. In H.D. Zimmer, R.L. Cohen, M.J. Guynn, J. Engelkanp, R. Kormi-Nouri, \& M.A. Foley (Eds.), Memory for action: A distinct form of episodic memory?. Oxford University Press. 